Journal of Machine Engineering, 2020, Vol. 20, No. 2, 18-38

ISSN 1895-7595 (Print) ISSN 2391-8071 (Online)

Received: 06 March 2020 / Accepted: 20 May 2020 / Published online: 24 June 2020

machine tool, numerical simulation, forced cooling, effects, development

\author{
Jerzy JEDRZEJEWSKI ${ }^{*}$ \\ Zdzislaw WINIARSKI ${ }^{1}$ \\ Wojciech KWASNY ${ }^{1}$
}

\title{
RESEARCH ON FORCED COOLING OF MACHINE TOOLS AND ITS OPERATIONAL EFFECTS
}

\begin{abstract}
The aim of this paper was to analyse in depth the existing research on the effectiveness of forced cooling and the directions in its improvement and development against the background of the increasing needs of machine tools and machining processes. The forced cooling methods used and their importance from the point of view of the development of machine tools are discussed. A detailed review of the state of the art in this field, including the latest research reports, is carried out. The essence and methods of forced cooling parameters improvement through holistic modelling, numerical simulations and optimization are presented. Moreover, the currently achievable effectiveness of forced cooling is illustrated with the results of the research conducted by the authors. Finally, conclusions are drawn and suggestions concerning the future research in this field are put forward.
\end{abstract}

\section{INTRODUCTION}

In order to identify the operational thermal behaviour of a machine tool and the multiaxial workpiece profile generation precision one must take into account the minimization of the impact of both the internal stationary and moving heat sources and the external heat sources, including the ones stemming from ambient temperature variation and heat accumulation in the machine tool's completely or partially closed spaces.

Because of the high dynamics of machining processes and the strong forces and high torques involved, models of generated power losses are highly complex and so are thermal error functions and the effective minimization of thermal errors by forced cooling. It is worth mentioning that rotational spindle speeds reach $50000 \mathrm{rpm}$, feed rates 30,40 and $60 \mathrm{~m} / \mathrm{min}$, accelerations $1-4 \mathrm{~g}$ and jerks $10000-30000 \mathrm{~mm} / \mathrm{s}^{3}$ (in multiaxis manufacturing synchronization for surface improving). Consequently, the generation of power losses and functions realizing effective forced cooling is highly complex. Also the complexity of modelling the numerical simulation and optimization of these processes is increasingly high and requires more advanced computer applications and systems and numerical control systems.

\footnotetext{
${ }^{1}$ Wroclaw University of Science and Technology, Department of Machine Tools and Mechanical Technologies, Wroclaw, Poland

${ }^{*}$ E-mail: jerzy.jedrzejewski@pwr.edu.pl https://doi.org/10.36897/jme/122769
} 
On the forced cooling modelling level, a detailed analysis of the current knowledge concerning forced cooling and its physical parameters (describing heat transfer conditions) and operating parameters (defining the economic and environmental effects) is essential.

Today forced cooling is commonly used in the assemblies of high-duty machine tools, especially the ones intended for precision machining. It is used not only by the leading machine tool manufacturers, but also by all the entities employing high speeds of motion in controllable axes. Because of the high energy intensiveness of such cooling its parameters should be so matched that machine tool thermal errors are minimal and the energy consumption is the lowest possible. Therefore it is necessary to create cooling models based on proper theoretical and practical knowledge.

Liquid cooling is characterized by high energy consumption. Since it is expensive, the matching of the cooling system's structural and operating parameters should be preceded by optimization in order to reduce energy consumption by the system to the minimum.

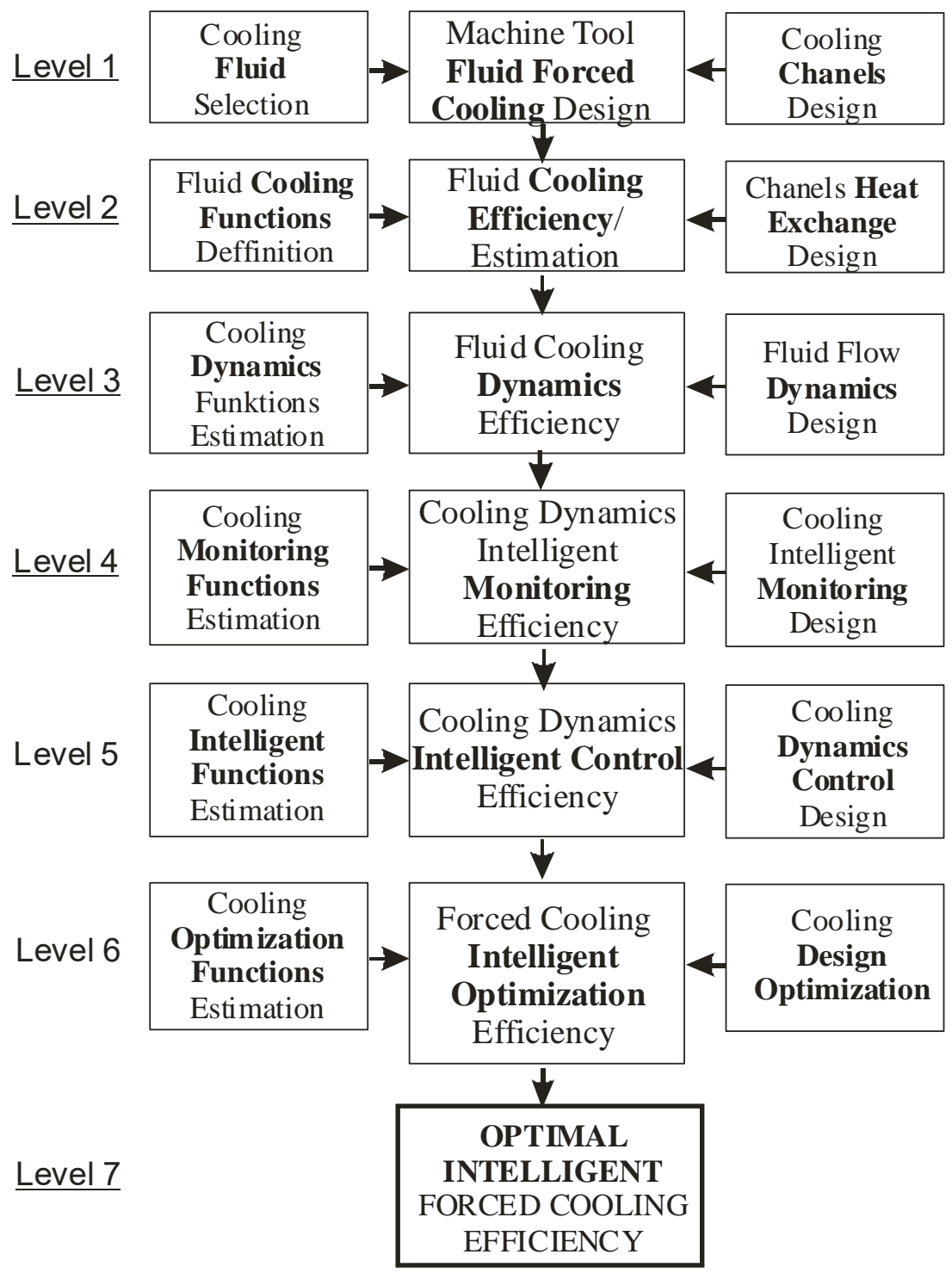

Fig. 1. Machine tool forced fluid cooling development levels 
In order to ensure effective and at the same time minimal cooling both the immediate surroundings of the heat sources and, as in the case of highly precise machine tools, the machine tool load-bearing structure and the housings of the work assemblies need to be taken into account.

The forced liquid cooling of machine tool assemblies can attain different levels of effectiveness, depending on the requirements concerning precision, automation and the degree of autonomy, which the machine tools must meet. In Fig. 1 the levels are presented as levels of cooling improvement in the process of cooling design, through the integration of functions and design solutions.

This paper presents the current knowledge on the modelling, numerical simulation and improvement of the forced cooling of the main machine tool assemblies (see Fig. 2).

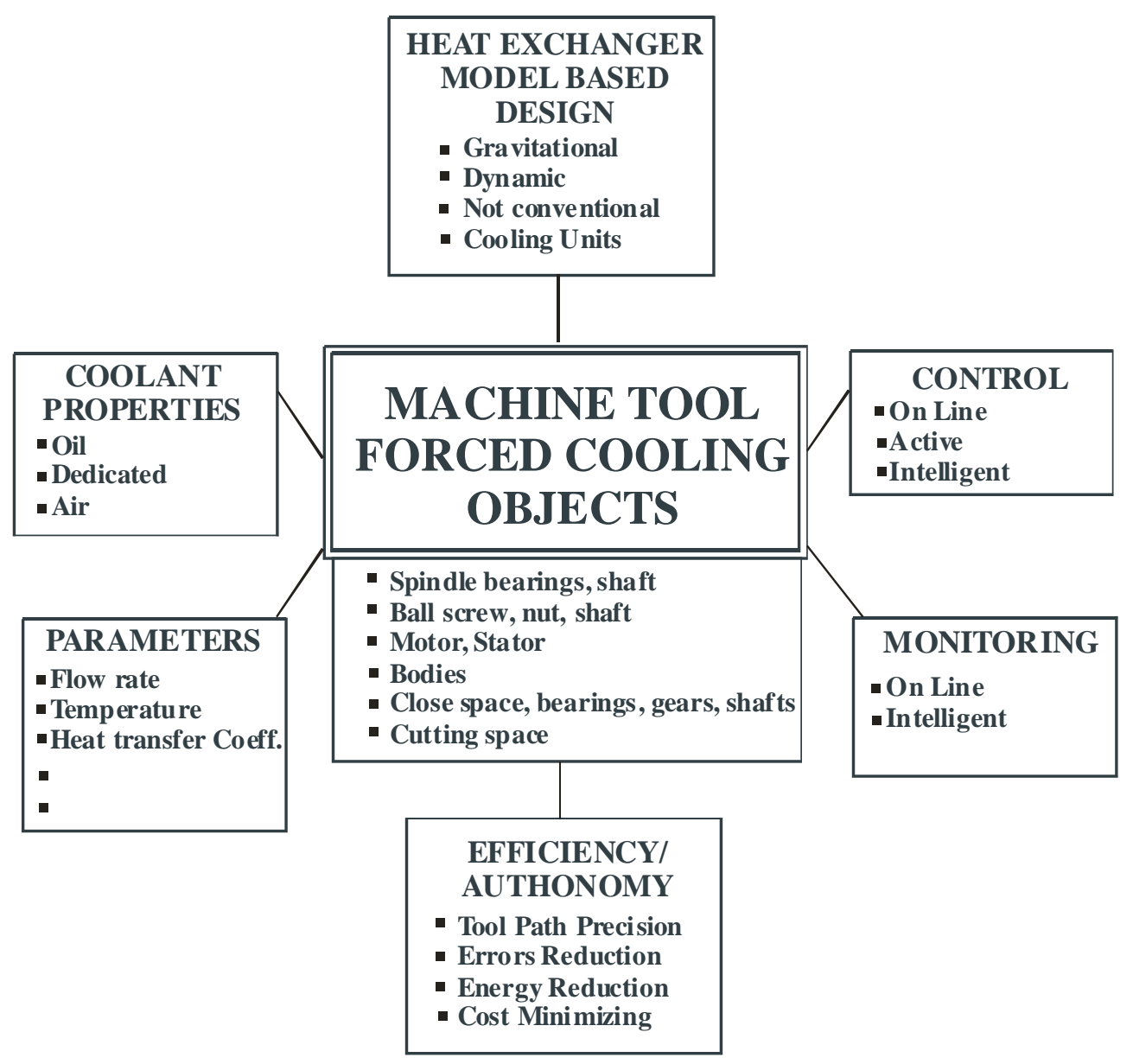

Fig. 2. MT structure forced cooling design development

The aim of its authors was to present a broad analysis of: cooling development, the impact of cooling parameters, numerical models of the intensive heat exchange induced by the motion of a liquid cooling agent in such areas of the machine tool structure as the inside of the headstock housing, the retainer of the spindle bearings, the stator of the electrospindle motor and so on. The models have been integrated with an in-house computing system for 
thermal and elasticity analyses of the mechanical structures of machine tools and with a highly advanced computing systems like ABAQUS. The above approach is an original one.

The models are analysed and verified for a turning/milling centre and a high-torque boring-milling centre, where a large amount of heat is generated and the complex mechanical structure necessitates the use of various forced cooling models. Finally, the beneficial effects of forced cooling and prospects for future improvements are presented and discussed.

\section{FORCED COOLING DEVELOPMENT BACKGROUND AND STATE OF THE ART}

Research on forced cooling began in the late 1960s and concerned spindle assemblies enabling an increase in rotational speed to over $3000 \mathrm{rpm}$ in turning machines. As rotational spindle speeds increased, so did power losses in bearing units, resulting in excessive rises in temperature and thermal deformations, which were difficult to reduce. At that time the first device for the external cooling of lathe bearings was invented by J. Jedrzejewski, J. Potrykus and W. Kwasny, for which a patent was applied in 1967 and granted in 1972 [1]. Using this device the effectiveness of cooling with air, oil and water was tested. Cooling with water was found to be much more effective than cooling with other media (Jedrzejewski 1973 [2]). Also trials of the forced cooling of the lubricating oil flowing in large amounts through spindle bearings were conducted in order to reduce the heating up of the latter (Jedrzejewski 1968 [3], Jedrzejewski 1989 [4]). This would lower the temperature of the bearings and reduce the displacements of the spindle, but caused a large increase in the moment of hydrodynamic friction in the spindle bearings. Also Peter de Haas 1975 [5] undertook attempts to remove heat from spindle bearing units by cooling the lubricating oil at a high flow rate of the latter whereby the thermal displacements of the spindle could be reduced by as much as 50\%. Together with Heisel 1978 [6] he also undertook attempts to externally cool the front spindle bearings with oil in order to increase the effectiveness of the compensation of thermal errors. Recently, similar studies were carried out by Vyroubal 2010 [7] for a vertical machining centre with an electrospindle. He noted, among other things, the different response times of the particular temperature measuring points.

Research on the modelling and numerical simulation of the cooling of spindles and electrospindles was conducted by Winiarski et al. 2006 [8], Winiarski 2008 [9], Winiarski 2010 [10]). The effectiveness of the external oil and water cooling of the electrospindle's bearings and stator at a spindle rotational speed of up to $40000 \mathrm{rpm}$ was investigated using a numerical model. Electro spindle torque influences on spindle bearings power losses. The displacement and heating up of the spindle, changes in running with bearings clearance, power losses, as major parameters useful in the design of cooling process, were studied as a function of the power applied to the spindle (Winiarski 2010 [10]).

Because of the high energy consumption by the systems of the forced cooling of machine tool assemblies attempts are made to comprehensively evaluate this energy consumption and to find more economical solutions. An example here is the evaluation made by Xirouchakis et al. 2009 [11] for the machine tool with all its accessories. It was shown that high pressure cutting lubrication consumes 45\%, MQL cutting - 26\% and spindle cooling 
$-28 \%$ of the energy. Brecher et al. 2012 [12] presented a possibility of reducing cooling costs. The reduction of energy consumption through the proper control (optimization) of the cooling of the coolant in the cooler was investigated. It was shown that thanks to the use of a frequency controlled compressor the energy consumption cost can be reduced to $70 \%$.

In this decade, research on improving the forced liquid cooling of machine tool assemblies has focused particularly on reducing forced cooling energy consumption by refining the cooling systems and reducing the output of the heat sources.

According to NSK research carried out by Miyaguchi and Arai 2013 [13], improvements of the ball screw nut return components, resulting in a higher value of the $\mathrm{n} \mathrm{dm}$ parameter, lead to higher cooling capability and higher positioning accuracy. Moreover, it was shown that a longer ball screw shaft requires less intensive cooling than a shorter one. For HSC spindle positioning precision it is crucial to reduce the spindle shaft thermal load through more efficient fluid cooling.

Xia et al. 2015 [14] showed experimentally that using fractal modelling and replacing the traditional helical geometry of cooling channels with a new design it is possible to increase convective heat transfer, reduce coolant pressure drop and obtain a more uniform temperature field and a more than twofold increase in performance.

Uhlmann et al. 2018 [15] developed a very promising self-cooling system concept and model (Uhlmann et al. 2020 [16]) for the linear direct drive of the machine tool table, equipped with a thermoelectric generator and a cooling plate. The water cooling unit's pump works without any external energy supply and its control is based on a model. In this system the coolant flow rate is regulated depending on the table unit's thermal stability demands. This cooling solution leads to a reduction in pump power and to the development of machine tool intelligent functions.

A number of authors, mainly Hellmich et al. 2018 [17], show that the dynamic changes in heat sources in the operating conditions of direct spindle drives require the on-line monitoring and active control of the behaviour of the forced liquid cooling system in order for cooling precision to be as high as possible and spindle displacements stably the lowest.

Denkena et al. 2018 [18] studied the internal fluid cooling of the spindle in a range of up to $20000 \mathrm{rpm}$ by a system of heat pipes. The spindle shaft axial displacement was reduced by $50 \%$, but the efficiency of this very complex cooling system was much lower than that of simple traditional internal water cooling.

According to the recent literature review carried out by Wegener et al. 2017 [19], the numerous studies into fluid-operated machine tool parts, including forced liquid cooling elements, are worthy of note. Interactions between the operation of the two kinds of components and their impact not only on the effectiveness of cooling and the reduction of thermal errors, but also on other important service properties of machine tools, the accuracy with which movements are generated in the controllable axes, service friendliness, energy savings, thermal load reduction and costs are highlighted. The paper recommends adaptive fluid supply, holistic modelling, optimization, total monitoring and intelligent control.

The above survey of research on the forced cooling of machine tools indicates that this kind of cooling is vital for the development of high performance machining and still needs to be improved. Therefore it seems worthwhile to present and discuss in more detail different ways of improving the forced cooling of machine tools. 


\section{MODELLING AND NUMERICAL SIMULATION - EXAMPLES OF MACHINE TOOL BEHAVIOUR IMPROVEMENTS AND DEVELOPMENT TRENDS}

\subsection{DISCUSSION OF COOLING PARAMETERS}

The decision about introducing liquid cooling into the machine tool structure stems from the need to ensure high operational machining precision and performance, to reduce the amount of heat generated in spindle and feed assemblies, which adversely affects their operating parameters, and to reduce the effect of ambient temperature on the accuracy of the tool path generated in the controllable axes.

It is expected that owing to forced cooling such machine tool quality indicators as warmup time efficiency and the stability of machining dimensional change over time will be maintained at a satisfactory level. When designing a liquid cooling system for a machine tool, one should define the location of the cooling, the geometry of the coolers, the dimensions of the surfaces of the coolant channels, the kind and properties and velocity of the coolant, the flow rate and the coolant temperature at the cooler's inlet and outlet.

The cooler's capacity for collecting heat from heat generation areas is described by the heat transfer coefficient on the channel surface. The value of this coefficient depends on the coolant's parameters, such as: velocity, viscosity, specific heat, density and thermal conductivity. Moreover, the cooler channel's profile and its shape and the coolant flow path length are of major importance. Depending on the configuration of coolant flow parameters (expressed by the Reynolds number), a laminar flow, a transient flow or a turbulent flow can occur. The turbulent flow results in much higher heat exchange (higher heat collection capacity) than that characterizing the laminar flow. But the turbulent flow increases coolant motion resistances, resulting in higher energy consumption, and can generate forced vibrations.

The heat actually transferred between the cooler exchanger and the coolant depends not only on the heat exchange coefficient and the exchange surface, but also on the difference in temperature between the cooler's wall and the coolant, determined by the rate of flow of the coolant and the latter's specific heat and initial temperature. The heat absorbed by the coolant must be carried away and dissipated beyond the cooler so that the temperature of the coolant redirected to the cooler inlet assumes the set value.

In order to increase cooling efficiency, coolants characterized by high specific heat capacity, low density and considerable heat conductivity should be preferred. Moreover, the coolant's low viscosity is advantageous since it results in lower flow power losses and favours the attainment of the turbulent flow at low velocities. For example, water provides much more effective cooling than the traditionally used oil in the same flow conditions. It is important that the coolant does not cause corrosion of the coolant channels and supply conduits. The properties of a coolant specially designed for use in machine tools are presented and compared with the properties of other coolants (Table 1).

The specific heat of the recommended coolant is twice higher than that of the often used oil VG2 and is close to the specific heat of water. 
Table 1. Properties of coolants at $20^{\circ} \mathrm{C}$.

\begin{tabular}{|l|l|c|c|c|c|}
\hline Property & Kind of coolant & Oil VG10 & Oil VG2 & Special coolant & Water \\
\hline Density $\rho\left[\mathrm{kg} / \mathrm{m}^{3}\right]$ & 882 & 880 & 1002 & 998 \\
\hline Specific heat $c_{p}[\mathrm{~J} / \mathrm{kgK}]$ & 1733 & 1922 & 4070 & 4182 \\
\hline Viscosity $v\left[\mathrm{~m}^{2} / \mathrm{s}\right]$ & $30.2 \mathrm{e}-6$ & $3.5 \mathrm{e}-6$ & $3.5 \mathrm{e}-6$ & $1.0 \mathrm{e}-6$ \\
\hline Conductivity $\lambda[\mathrm{W} / \mathrm{mK}]$ & 0.116 & 0.16 & 0.49 & 0.604 \\
\hline
\end{tabular}

From the cooling location and method point of view one can distinguish:

- cooling forced by coolant motion through narrow channels in the sleeve in which, e.g., a motor stator, spindle bearings or a ball screw nut are set;

- cooling forced by the flow of a coolant through holes in rectangular cooling bars mounted on the surface of a body to prevent its walls from heating up due to ambient convection and radiation or heat sources inside the body;

- cooling forced inside bodies by the direct flow of a coolant on the surface of slideways, spindles or ball screws, shafts and nuts;

- dissipated cooling, effected by spraying a coolant onto the inner surfaces of body walls or rotating elements (e.g., toothed gears);

- cooling occurring in heat pipes.

Therefore when designing cooling systems one needs to holistically model the processes of heat generation and removal and optimize the coolers' design and the cooling parameters, which is the subject of the subsequent chapters.

\subsection{MODEL OF HEAT EXCHANGE}

Before modelling and numerically simulating the cooling system of a machine tool, one must determine the necessary design parameters of the coolers and the coolant in thermally unstable states to ensure the temperature rises and thermal displacements allowable for the machine tool's operating conditions. Simulations should supply information about the kind of cooling agent, its temperature at the cooler's inlet/outlet, the flow rate and the necessary heat transfer surface in the cooling channels. It should be noted that the temperature variation range at the inlet to the cooler is controlled since it is connected with the heat exchanger's complexity and energy consumption. Moreover, aiming at a reduction of the total cooling system costs one should determine the minimal coolant flow and the external cooling system's ability to dissipate the heat absorbed by the coolant from the machine tool. Therefore when designing coolers, it is necessary to optimize their structure and parameters, which is easier done using the simplest, but sufficiently accurate, mathematical models. Since the aim of the authors' investigations was the quick improvement of machine tool prototypes the above liquid cooling modelling methodology was deemed suitable.

The modelling of liquid cooling (Fig. 3) applies to:

a) - coolers in which the coolant motion path is imposed by narrow helical channels situated around heat sources,

b) - dissipated cooling effected by feeding the coolant onto the interior walls of the housing and the rotating components of the gear. 


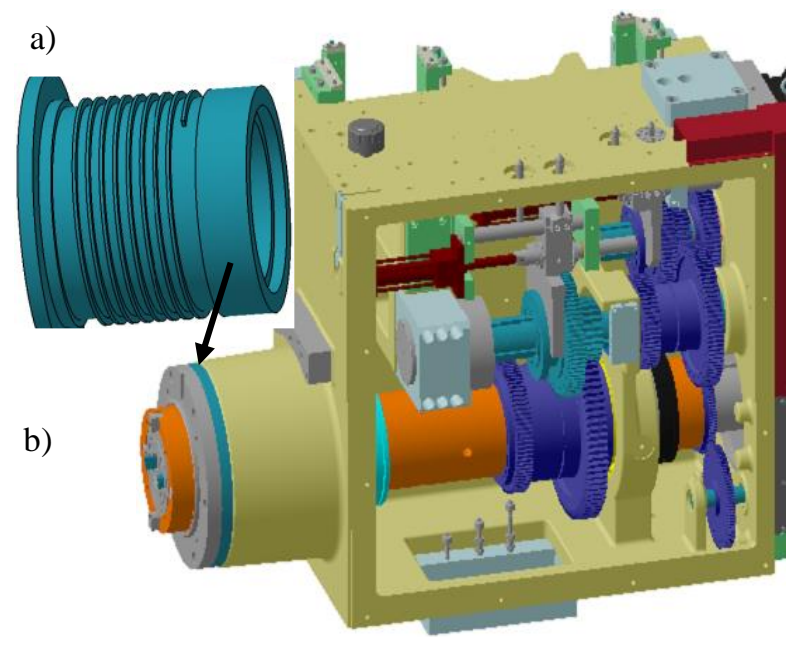

Fig. 3. Exemplary structure of cylindrical cooler with grooves running along screw line (a) and cooled interior of headstock (b) with its components marked with different colours (Jedrzejewski et al. 2014 [20])

The modelling of channel coolers involves the FEM and FDM discretization of the cooler housing and the channel space (Fig. 4) and the heat balance equations for the unsteady transfer of heat in the coolant flow conditions. Discrete volume elements are connected in series, consistently with the direction of flow of the coolant. The temperature of the coolant (whose initial temperature is known) changes as the latter flows through a cooler element, due to the absorption of heat from the cooler walls. The temperature of the coolant at the outlet from the element is at the same time the temperature at the inlet to the next element. Thus the heat exchange in the latter element takes place at a different coolant temperature than in the preceding element. The balance equation for a single element with a coolant flowing through it (Fig. 5).

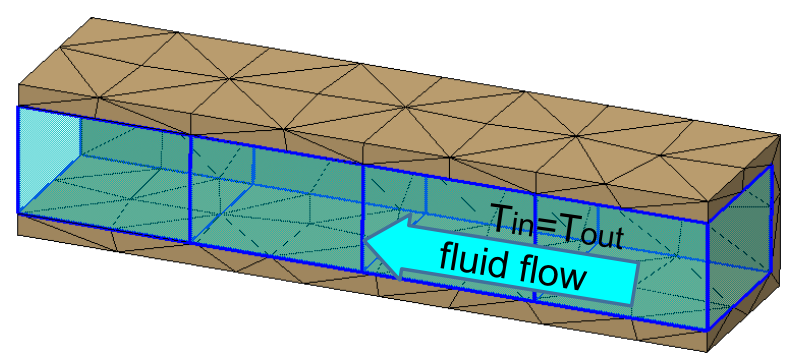

Fig. 4. Discretization of fragment of rectilinear cooler housing and coolant channel

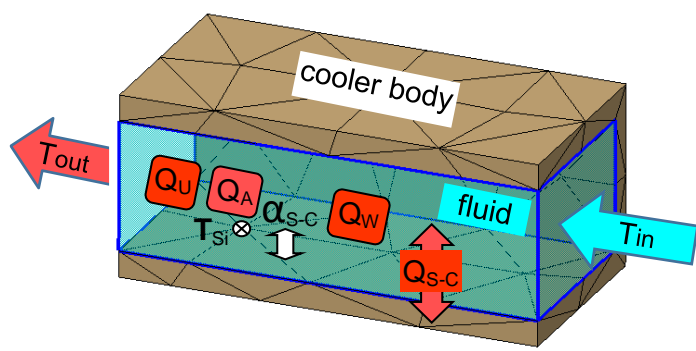

Fig. 5. Model of heat exchange in discrete element of coolant flowing in cooler channel 
The assumptions shown in Fig. 6 were made to model the heat exchange inside a headstock containing gears, where lubricating-cooling oil is fed onto rotating kinematic elements.

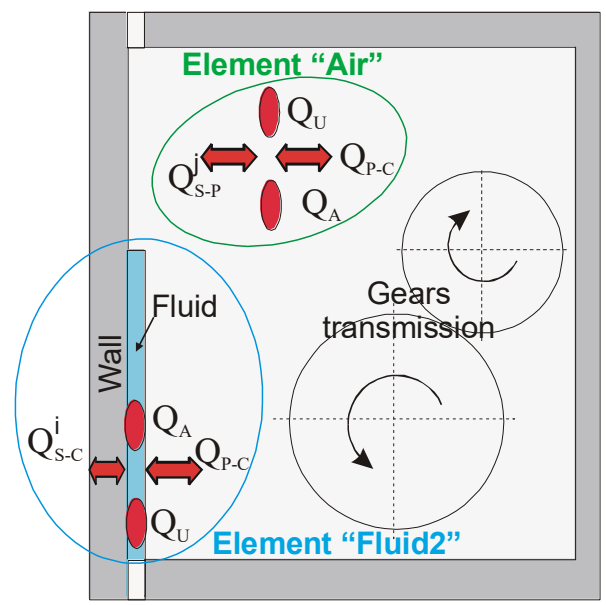

Fig. 6. Model of heat exchange inside headstock, which takes into account air and lubricating oil contributions

Discrete element Fluid 2 is used for a coolant flowing down the surfaces inside the housing, which simultaneously exchanges heat with air. Discrete element Air is used to model the heat exchange between air and the surfaces inside the housing, which are not washed by the coolant. The air can circulate in the closed headstock space and flow through the latter in order to cool it.

The use of the above models of the heat exchange inside coolers and complex housings requires considerable experience, preferably based on experimental analyses and the available literature. The coefficients of forced convection must be accurately calculated and the interior surfaces must be properly divided into discrete elements.

The liquid cooling models based on the multielement discretization of the cooler channel with a liquid represent a significant improvement on the previous models. The previous models were based on only one liquid element representing the whole cooler, whereby they were much simplified. A novelty is the model of the heat exchange through the downflow of lubricating-cooling oil fed onto the interior walls and the rotating gear elements, which is mainly applicable to high-duty headstocks with a high spindle torque.

\subsection{HEADSTOCK LIQUID COOLING MODEL}

The structure of the headstock of a horizontal drilling milling machine (Fig. 3 ) for the precision machining of large-size and heavy objects was used to verify the accuracy of the new method of modelling forced cooling. Since it must ensure high torques (3354 Nm, $2500 \mathrm{rpm}, 22 / 26 \mathrm{~kW}$ ) the headstock is a thermally complicated structure containing gears and the very stiff bearings of the spindle supports. Therefore the gears and the bearings of their shafts need to be continuously lubricated with oil. The lubrication of the spindle bearings with oil mist certainly is not energy-saving. Consequently, large heat fluxes are generated, 
resulting in high temperature rises and large thermal displacements of the spindle. A diagram of the spindle liquid cooling is shown in Fig. 7.

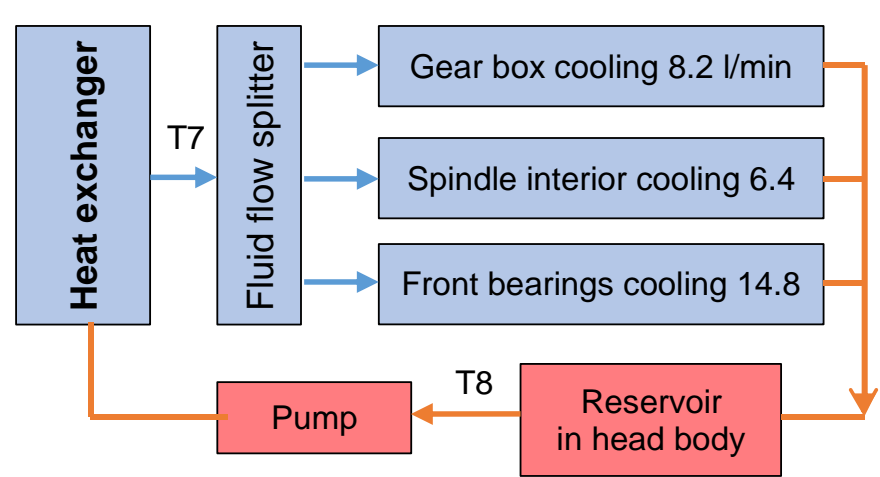

Fig. 7. Diagram of oil flows in headstock cooling system

The oil cooling system (Fig. 7) directs the oil cooled down to the required temperature (T7) in the main heat exchanger to a splitter from where the oil flows in separate streams (at the specified flow rate) to the particular coolers of the headstock. The heated up oil is carried off to a transitional reservoir and pumped to an external heat exchanger in order to lower its temperature.

Figure 9 presents the results of temperature measurements in the points shown in Figs. 7 and 8, performed for 6 hours of headstock idle operation at a speed of $2500 \mathrm{rpm}$. The cooling system was working over the whole measurement time, ensuring the cooling oil flow rates specified in Fig. 7. The temperature (T7) of the cooled down oil (Fig. 7) was initially lower than in the steady phase. Moreover, the external cooling control system guaranteed a low oil temperature $T 7$ variation amplitude of about $0.4^{\circ} \mathrm{C}$ (Fig. 10) over the whole time of the experiment. As a result, the amplitude of the measured temperature (T3) of the cooling sleeve was as low as $0.1^{\circ} \mathrm{C}$. Owing to this, the variation cycle did not have to be modelled and the temperature $T 7$ at the inlet to the headstock coolers could be assumed to change monotonically from $17^{\circ} \mathrm{C}$ to $20^{\circ} \mathrm{C}$ (see Fig. 9).

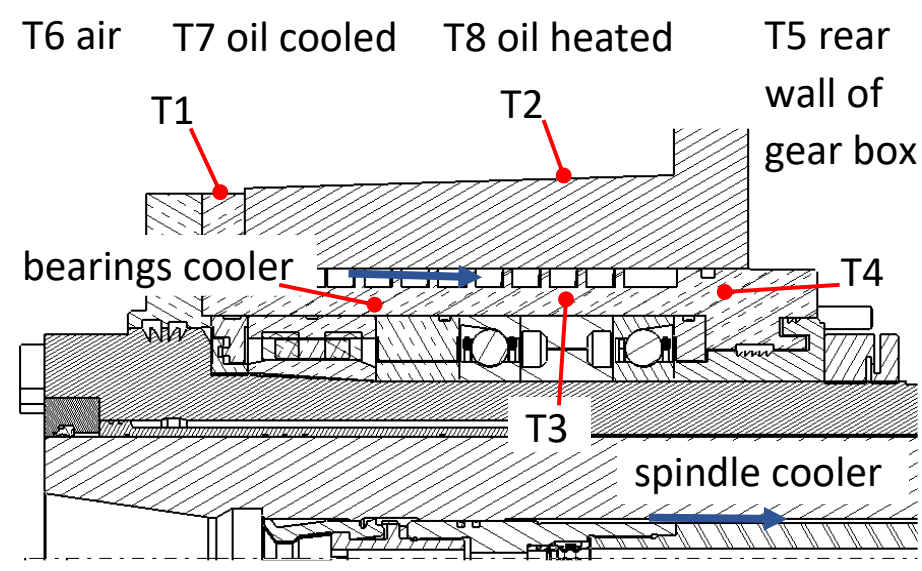

Fig. 8. Locations of temperature measuring sensors 
By properly setting the air temperature controlling devices (Fig. 9) it was ensured that the average temperature changed in the narrow range of $19-20^{\circ} \mathrm{C}$ and the temperature variation amplitude of $1^{\circ} \mathrm{C}$ was maintained (Fig. 10). The initial temperatures in the measuring points: $T 1, T 2, T 3, T 4$ and $T 5$ differed by about $2.5^{\circ} \mathrm{C}$. The differences made verification somewhat difficult.

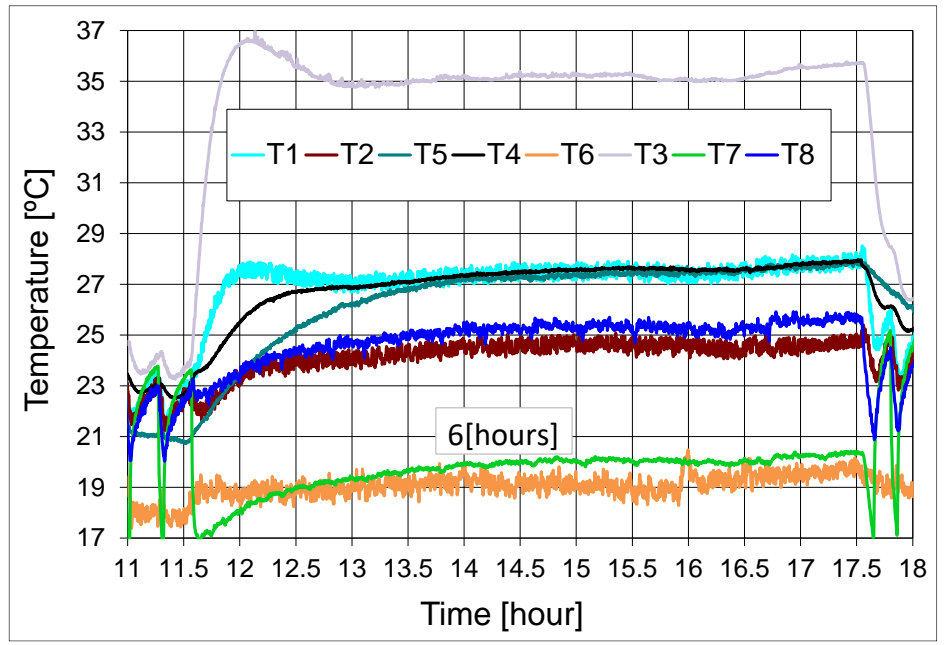

Fig. 9. Temperatures measured over 6 hours of headstock operating time with cooling system active

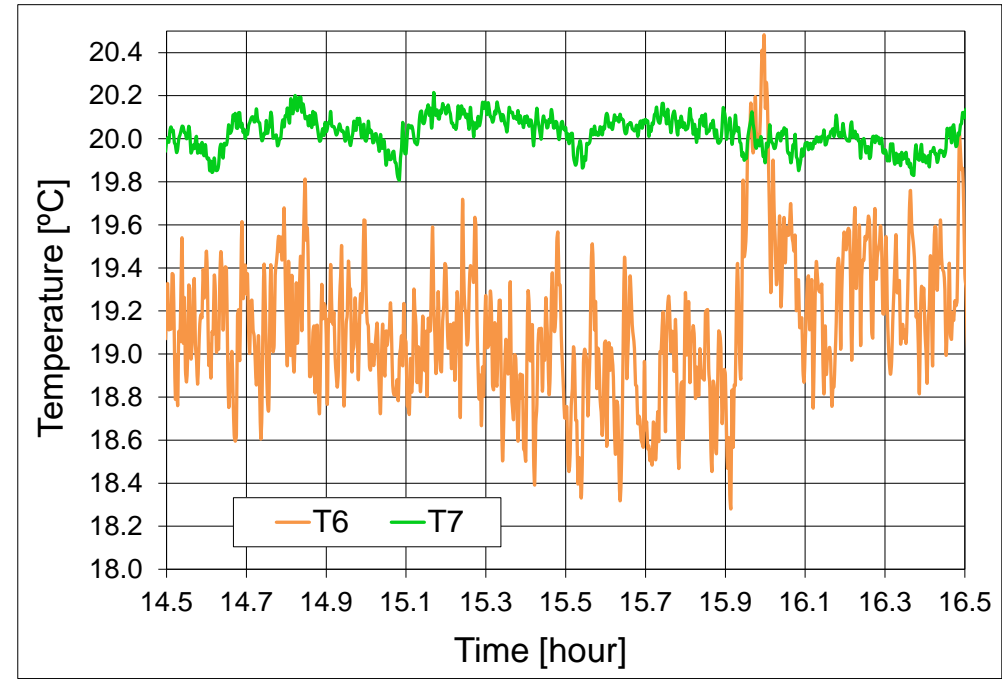

Fig. 10. Measured amplitude of oil inlet temperature $T 7$ and ambient temperature $T 6$ in selected time period

In order to carry out simulations of temperature variation a geometry model corresponding to the structure of the tested headstock was created and discretized (Fig. 11). The discretization covered all the coolers.

Temperature computations were performed using in-house computing system SATO (Winiarski et al. 2006 [21], Kowal et al. 1990 [22], Jedrzejewski et al. 2014 [23]) with the liquid cooling modelling method implemented. When creating the headstock temperature model in SATO, the following were assumed: 
- unsteady heat conduction for 6 hours in all the assembly components and heat transfer through the joints;

- heat flux generation in the sets of spindle bearings, the gears and the bearings supporting the shafts, for a drive path ensuring the highest spindle speed of 2500 rpm (idle run);

- the factory fitting of the mounting of the bearings, their post-assembly loads (preload) and lubrication parameters;

- the rates of the flow of the liquid through the coolers as in Fig. 7;

- convectional and radiational heat exchange inside the housing and to the environment.

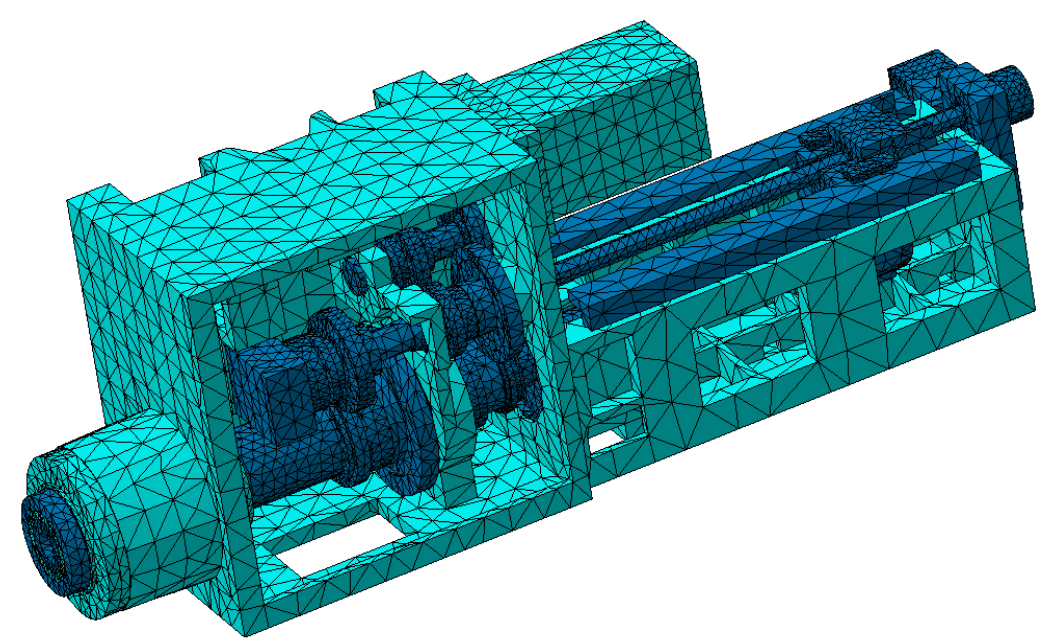

Fig. 11. Discrete model of headstock mechanical structure and built in coolers

The quality of the liquid cooling modelling method was also evaluated in the unsteady period of headstock operation. The transient temperature curves for the sleeve cooling the front spindle bearings are compared in Fig. 12. The shape of the curve of the computed temperatures indicates good tracking of measured temperature $T 3$. The deviations observed in the period of its fastest rise, amounting to $2.5^{\circ} \mathrm{C}(18.5 \%)$, are slightly larger than the ones in the steady state $1.5^{\circ} \mathrm{C}(12.2 \%)$. Considering the high complexity of the modelled thermal processes and that modelling related just to the heat source centre, this is good agreement.

Figure 13 shows a comparison of the temperatures for a measuring point located on the rear wall of the headstock, aimed at verifying the model of the heat exchange inside the housing cooled with oil lubricating the gears, their shafts and bearings and the headstock walls. Also in this case, the error in the period of the fast rise of temperature $T 5$ is larger than the one in the steady state. Nevertheless, the shape of the computed and measured temperature curves is similar and the observed deviations are acceptable.

In order to more fully verify the accuracy of the cooling model the measured thermal displacements (Fig. 14) of the headstock were compared with the computed ones. The good agreement between the thermal displacements indicates that the obtained temperature distribution, which takes into account the effect of a very complex modelling the liquid cooling in the headstock, is correct. 


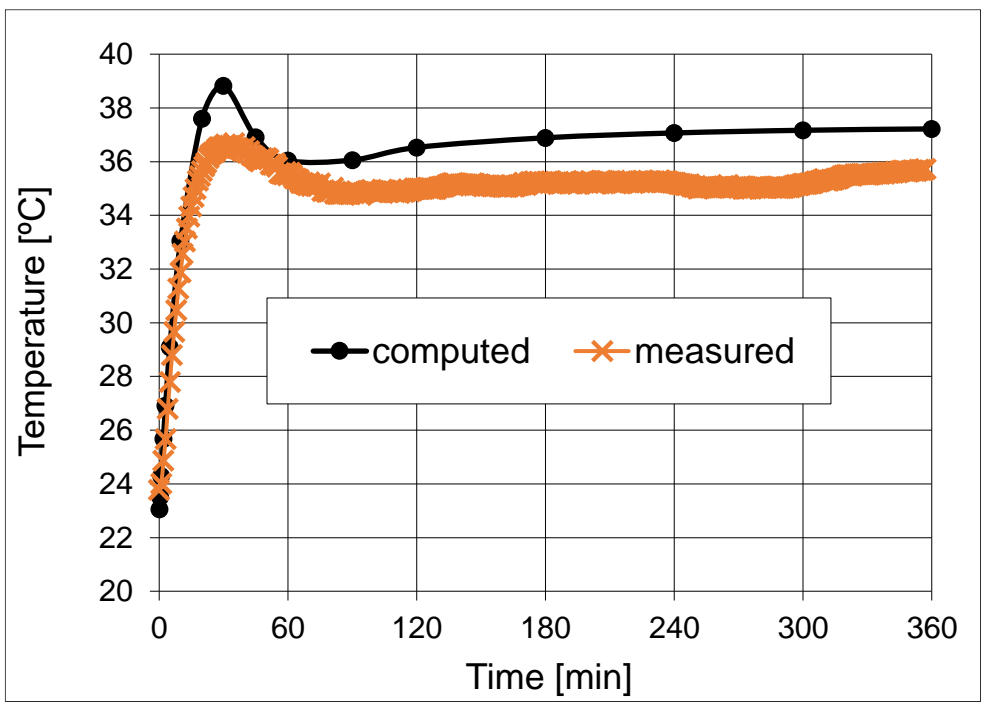

Fig. 12. Transient temperature $T 3$ for sleeve cooling of the front spindle bearings

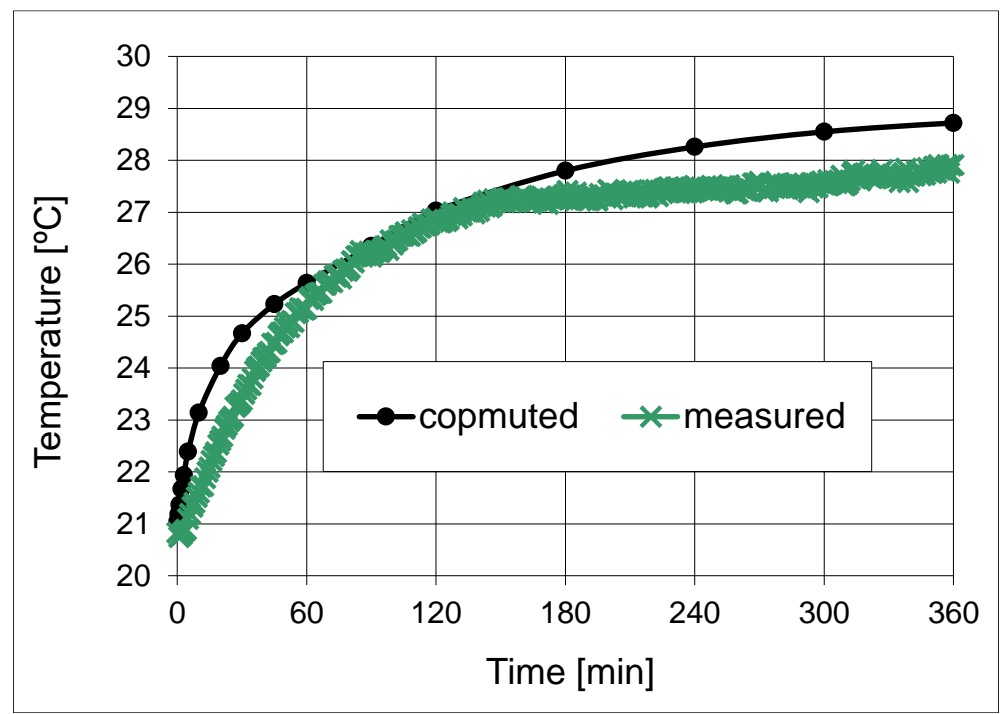

Fig. 13. Transient temperature $T 5$ of rear wall of the headstock for integrated bearings, spindle and gears cooling

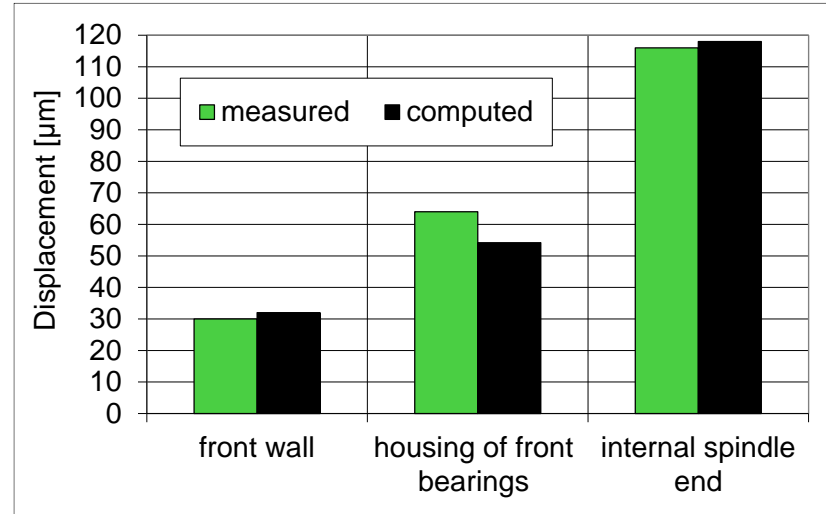

Fig. 14. Measured and calculated thermal axial displacements in selected drilling milling headstock points for integrated bearings, spindle and gears cooling $2500 \mathrm{rpm}, t=360 \mathrm{~min}$ 


\subsection{REDUCTION OF ELECTROSPINDLE THERMAL STABILIZATION TIME THROUGH DELAYED SWITCHING ON OF COOLING}

A major problem relating to the thermal behaviour of spindle assemblies is the long time of reaching stable axial stiffness. Seeking a solution to this problem, the authors carried out an analysis of the forced cooling of the bearings and the stator, assuming that the liquid cooling system starts working with delay $t=0,10,15$ and 20 min relative to the starting of the electrospindle.

a)

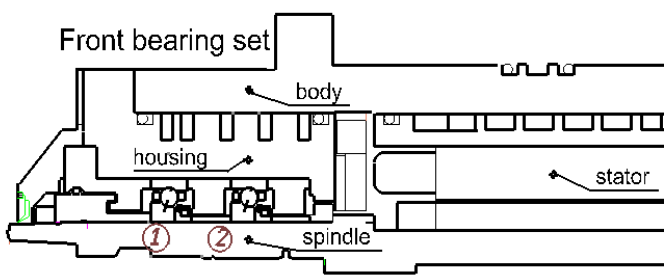

b)

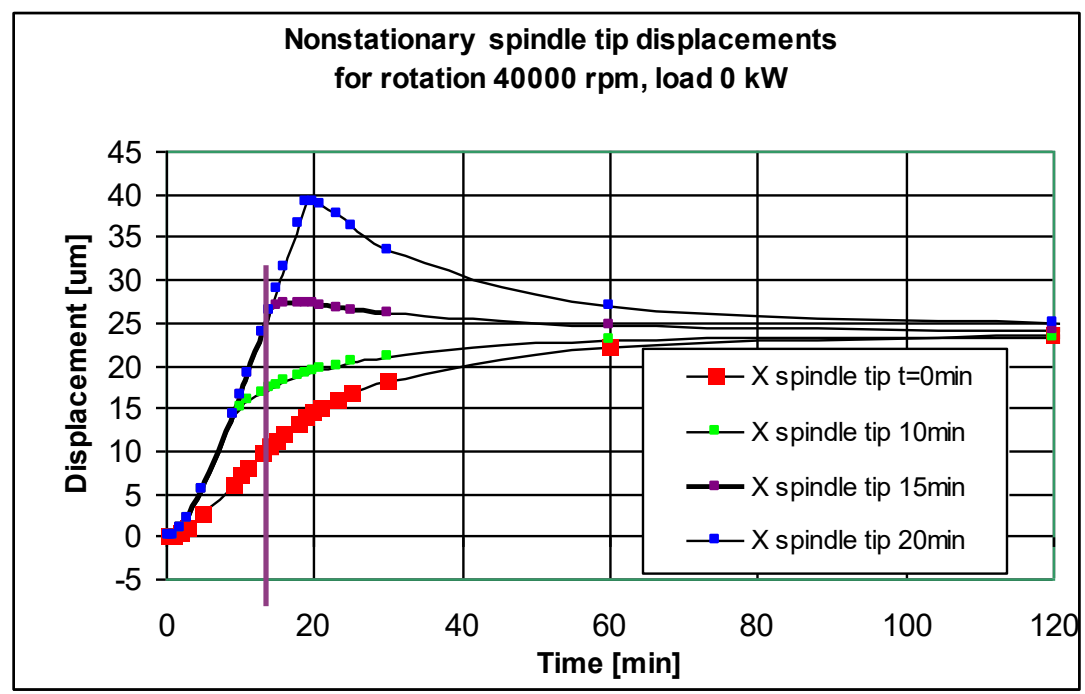

Fig. 15. Electrospindle (40 $000 \mathrm{rpm}$ ) design with liquid cooling of stator and bearings retainer (a), thermal spindle tip displacements for switching on cooling with delay $t(\mathrm{~b})$

It was found, that for the particular electrospindle design (Fig. 15a) the period and value of dynamic changes in axial spindle tip displacement could be decreased if the cooling system started working as late as 15 minutes after starting the electrospindle (Fig. 15b).

Switching on cooling later than indicated above results in displacements exceeding the steady state displacement value.

This experiment shows that it makes sense to control cooling switch-on time on the basis of, e.g., signals from an intelligent machine tool thermal state monitoring system.

\subsection{EFFECTS OF LIQUID COOLING ON ROTARY TABLE}

In the case of high precision five-axis machining centres it is necessary to minimize the thermal errors contributed by the rotary table directs drive. A simplified physical model 
of such a table directly driven by a FANUC torque motor is shown in Fig. 16. At the maximum torque the motor generates power losses amounting to over $7.5 \mathrm{~kW}$. Moreover, significant heat is generated in the large main axial-radial roller bearing supporting the rotary plate of the table and in the auxiliary ball bearing supporting the lower part of the spindle.
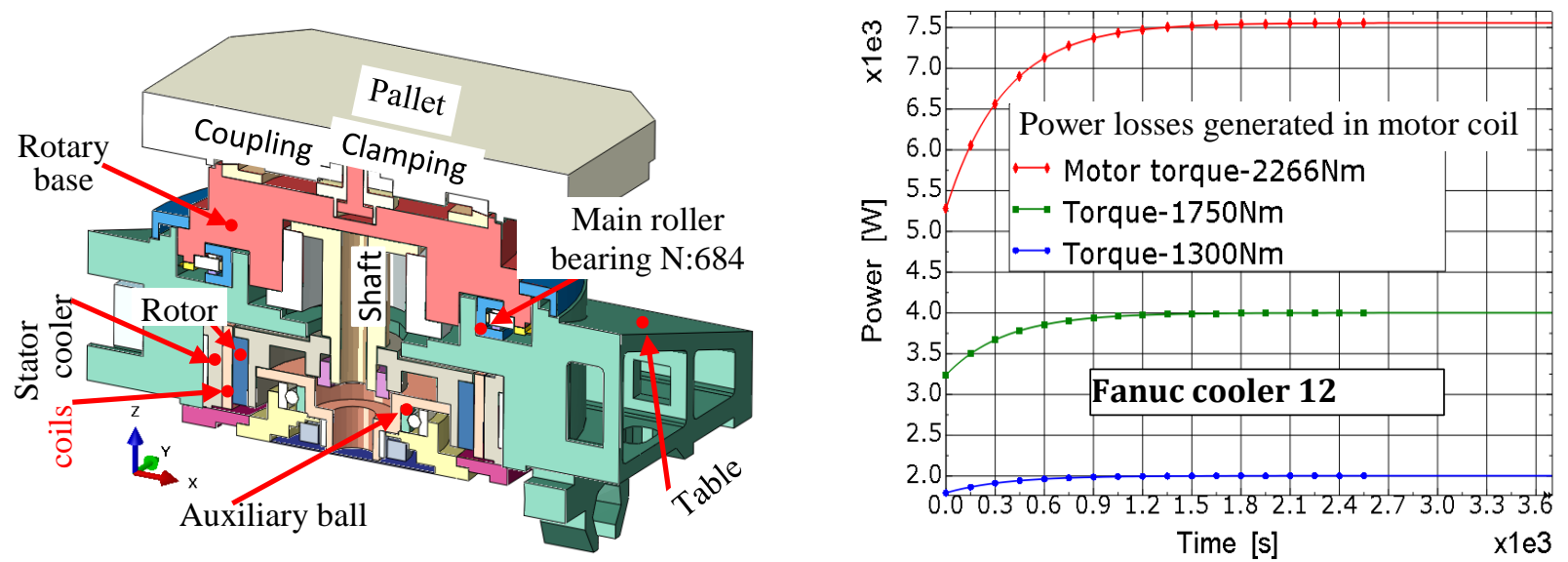

Fig. 16. Physical rotary table model and power losses generated in stator coils for rotor speed $5 \mathrm{rpm}$

In order to analyse temperature and displacements a thermomechanical FE model was created in ABAQUS.

As part of model creation the following were considered:

- heat generation in the stator coils of the FANUC motor and in the roller bearing and the ball bearing;

- elastic deformations and mechanical interactions having an influence on clearances, interferences and bearings stiffness;

- steady and transient heat conduction, including thermal conductance between connected parts;

- heat exchange between the motor stator cooler and the flowing fluid;

- convective and radiation (including cavity radiation) heat transfer to the outer environment at the rotary table surfaces;

- boundary displacements in the table guideways and feed drive screw nuts housing.

Different types of stator coolers, different kinds of cooling fluids and different fluid flow rates were considered when analysing heat removal effects.

The results of rotary table temperature and displacement distribution simulations for the continuous operation $5 \mathrm{rpm}$ of the motor cooled with a water flow of $15 \mathrm{l} / \mathrm{min}$ and loaded with a torque of $2266 \mathrm{Nm}$ are presented in Fig. 17 and Fig. 18.

In order to determine the best motor cooler design three types of coolers, water as the cooling agent, the water flow rate of $15 \mathrm{l} / \mathrm{min}$ and the continuous running of the motor loaded the maximum torque of $2266 \mathrm{Nm}$ were assumed.

The simulations of the thermal behaviour of the rotary table carried out for the three cooler designs showed that the factory-provided 12-groove cooler of the FANUC motor driven rotary table ensured the highest stator windings water cooling effectiveness (Figs. 18 and 19). 


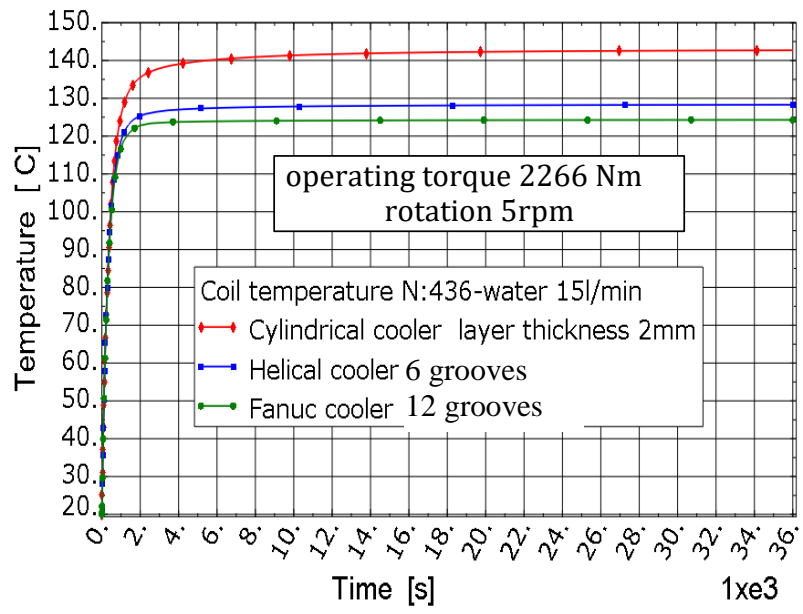

Fig. 17. Stator coil temperature for three types of cooler

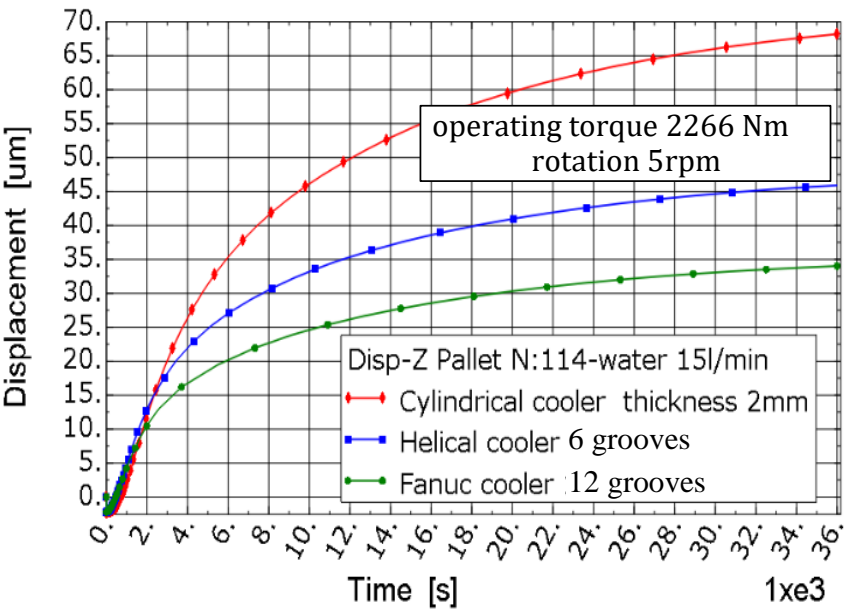

Fig. 18. Thermal displacements of rotary table along $Z$-axis for three types of cooler

The simulations of the effect of the type of coolant (Fig. 19) on the thermal displacement of the centre of the table plate show a considerable superiority of water and the special liquid over low-viscosity VG2 oil. Figure 20 shows the effect of the coolant flow rate on the displacement of the table. The twofold increase in the flow rate from $15 \mathrm{l} / \mathrm{min}$ to $30 \mathrm{l} / \mathrm{min}$ resulted in a decrease in thermal displacement Disp- $X$ from $27 \mu \mathrm{m}$ to $20 \mu \mathrm{m}$ and in displacement Disp- $Z$ from $36 \mu \mathrm{m}$ to $24 \mu \mathrm{m}$.

The investigations have shown that the use of oil as the cooling agent is inadvisable and the recommended special fluid ensures good cooling intensity close to that of water (Fig. 20). It has also been shown that the increase in the water flow rate in the motor windings cooler from the manufacturer recommended $15 \mathrm{l} / \mathrm{min}$ to $30 \mathrm{l} / \mathrm{min}$ significantly reduces the table centre displacement along axis $Z$.

It emerges from the above investigations of the liquid cooling of the rotary table of the precision machining centre that the use of this kind of cooling significantly reduces the axial displacements of the table and so makes their precise compensation easier. Cooling efficiency reaches about $71 \%$.

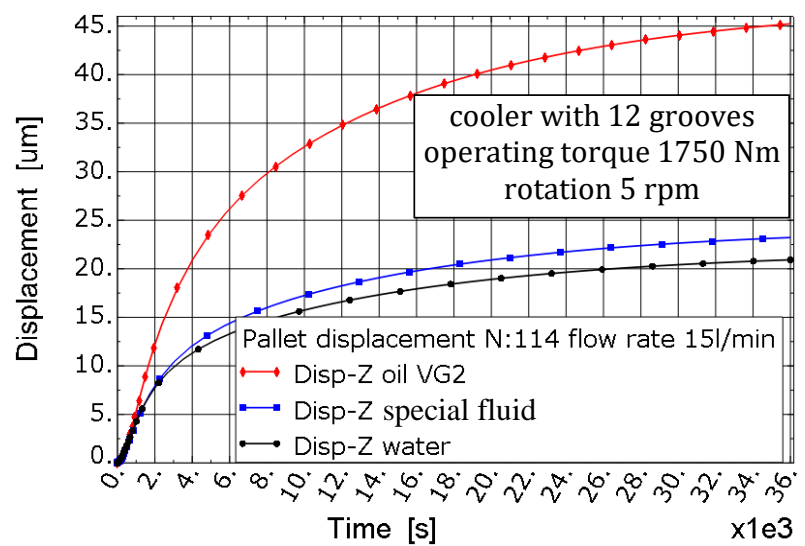

Fig. 19. Thermal displacements of the table plate centre for different coolants

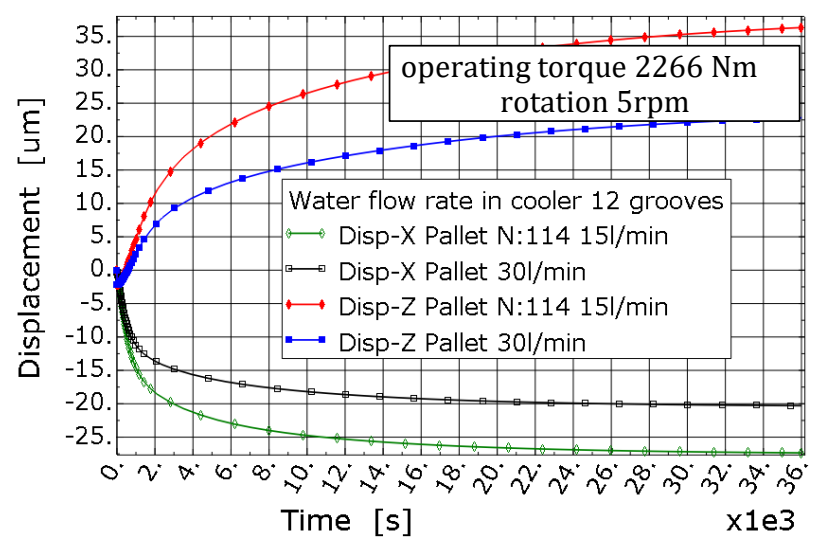

Fig. 20. Thermal displacements of the table plate centre for 15 and $30 \mathrm{l} / \mathrm{min}$ flow rates 


\subsection{EFFECTS OF THE MILLING DRILLING MACHINE HEADSTOCK OIL COOLING}

The heavy duty headstock thermal model was the base for numerical simulation of the temperatures along external headstock spindle (see Fig. 21) in steady state (see Fig. 22) for:

- No cooling,

- Front bearings (A) cooling,

- Internal spindle $(B)$ and bearings $(A)$ cooling $(A+B)$,

- Headstock interior/gears transmition $(C)$ and bearings with internal spindle $(A+B)$ integrated cooling $(\mathrm{A}+\mathrm{B}+\mathrm{C})$.

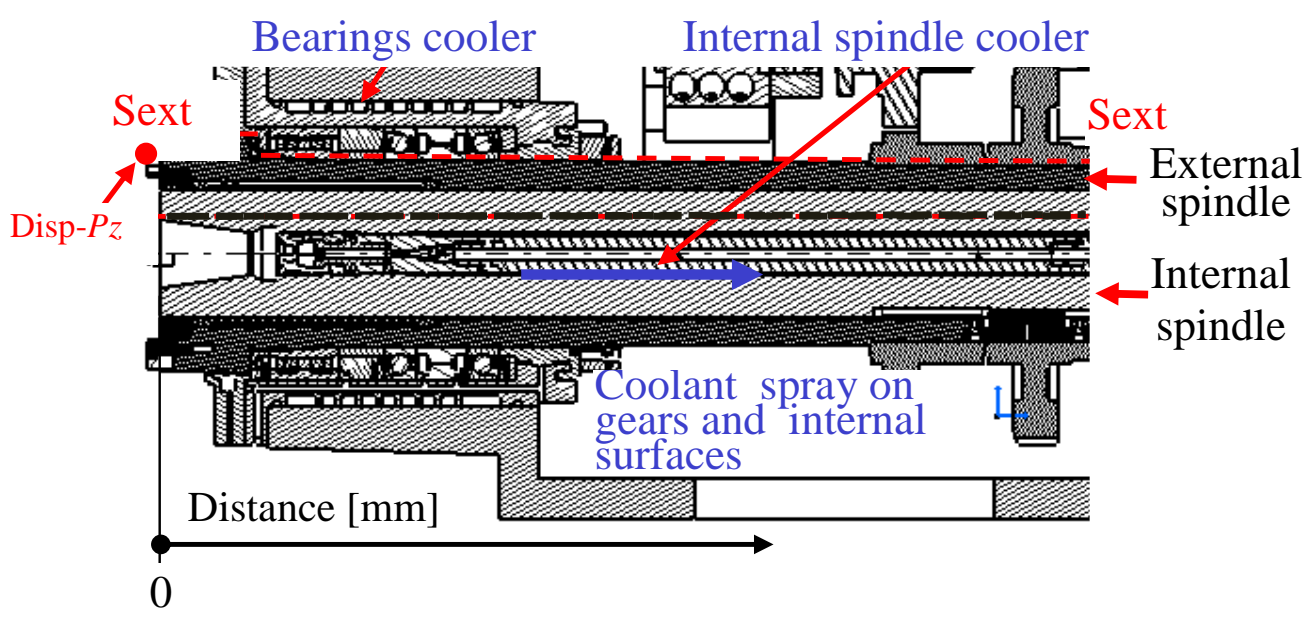

Fig. 21. The Headstock spindle assembly cooling structure, external spindle temperature estimation surface line Sext-Sext and axial displacement of external spindle estimation point $\mathrm{Pz}$

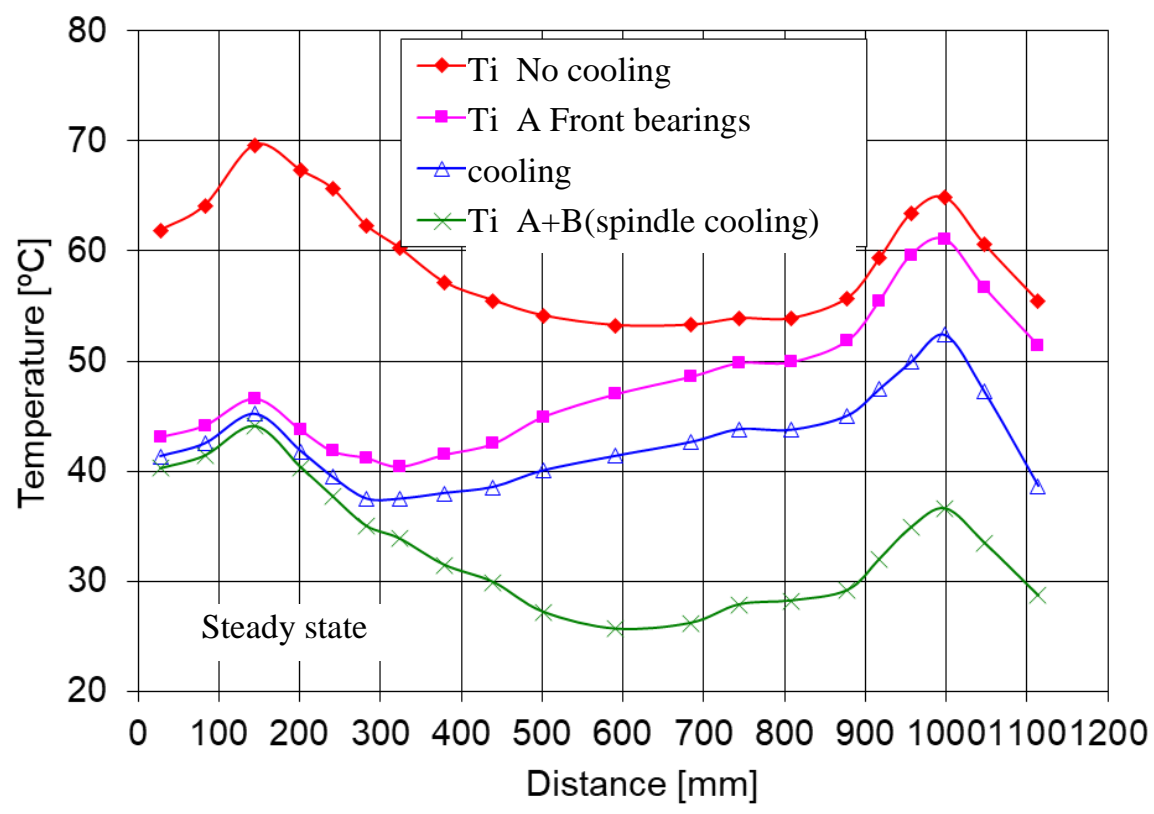

Fig. 22. External spindle temperatures along surface Sext-Sext line for selected cooling cases, in study state, after 360 min spindle idle run with $2500 \mathrm{rpm}$ 
Cooling of only (A) and cooling the bearings with internal spindle $(A+B)$ leads to visible decreasing of external spindle temperature (thermal load), but significant cooling effect gives the headstock total integrated cooling $(\mathrm{A}+\mathrm{B}+\mathrm{C})$.

The bearings units power losses impact, front and rear on the temperature of external spindle is significant, both for bearings only cooling and together with internal spindle as well as for integrated cooling $(\mathrm{A}+\mathrm{B}+\mathrm{C})$. It means that bearings cooling is not enough efficient. The efficiency of integrated cooling should be increased.

Forced cooling of the headstock assembly depending on spindle run time strongly influences on the external spindle axial displacements (see Fig. 23). Impact of front bearings unit only cooling and with internal spindle cooling is significant and similar.

Crucial impact on external spindle thermal displacement results from integrated cooling $(A+B+C)$. Such a cooling of the heavy duty headstock is suggested for reduction of external spindle thermal error in operational conditions. Efficiency of integrated headstock cooling in external spindle displacements reaches about 71\%. Residual displacement $100 \mathrm{~mm}$ requires compensation.

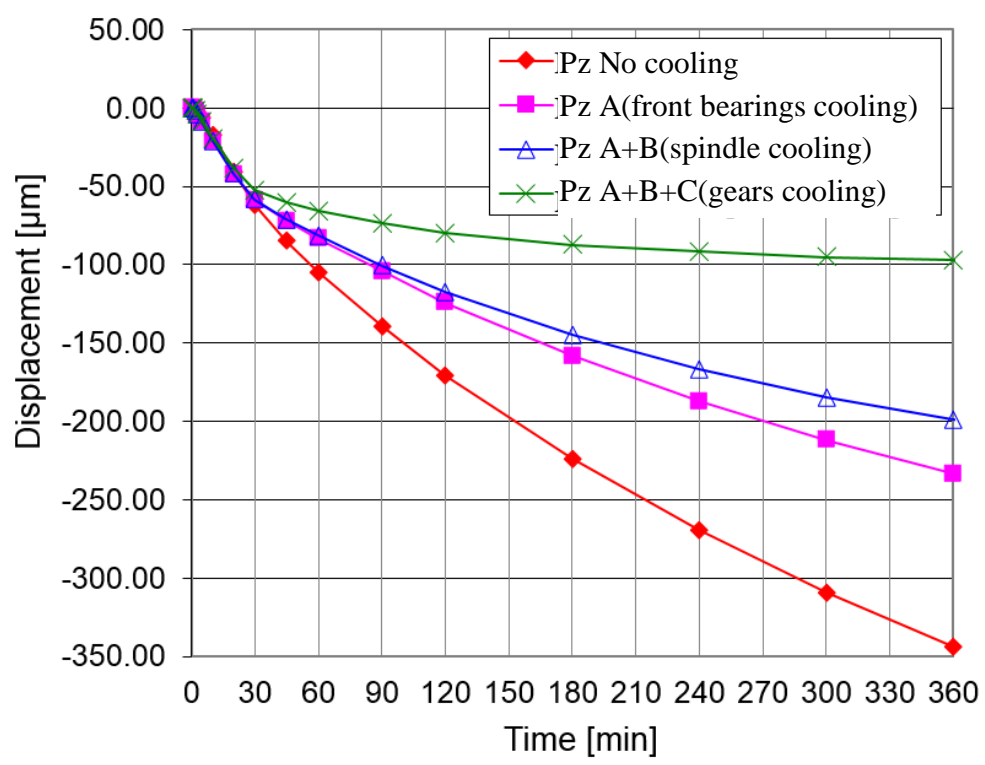

Fig. 23. Thermal axial displacements of the external spindle tip $(P z)$ for assumed cooling cases depending the idle running time with $2500 \mathrm{rpm}$

\subsection{EFFECTS OF BALL SCREW COOLING}

The thermal displacement of the ball screw shaft in the turning centre's feed control axis directly contributes to the machined part error. The reduction of this error through the reduction of the heating of the ball screw unit components by internal and external heat sources has an important impact on machining performance. The ball screw positioning error model and the power losses model essential for the former are very complex and so is the changeable ball screw unit load affecting heat generation. The problem was described in 
detail by the authors in Jedrzejewski et al. 2019 [24] and was considered when designing the cooling process for the turning centre ball screw drive unit.

On the basis of FEM simulations and experimental tests low density oil and its flow rate of $6 \mathrm{l} / \mathrm{min}$ were selected for the forced fluid cooling of the ball screw shaft and nut. Computations were performed using the in-house SATO system enabling the very detailed modelling of power losses.

Without cooling the temperature of both the ball screw shaft and the nut increases excessively and cause not acceptable positioning error. For the oil flow rate of $6 \mathrm{l} / \mathrm{min}$ at the feed of $6 \mathrm{~m} / \mathrm{min}$ the cooling of the nut reduces the temperature more than the cooling of the shaft (Fig. 24). The temperature is reduced by as much as $60 \%$. This cooling efficiency was confirmed by the research results reported by NSK [24].

The displacements of TCP in the case of the integrated cooling of the screw shaft and nut reached $62 \%$. Moreover, the cooling of the nut is almost as efficient as the integrated cooling of the shaft and the nut and it is much cheaper since, the design of internal shaft cooling is much more technologically complex. Therefore nut cooling is commonly preferred by machine tool builders.
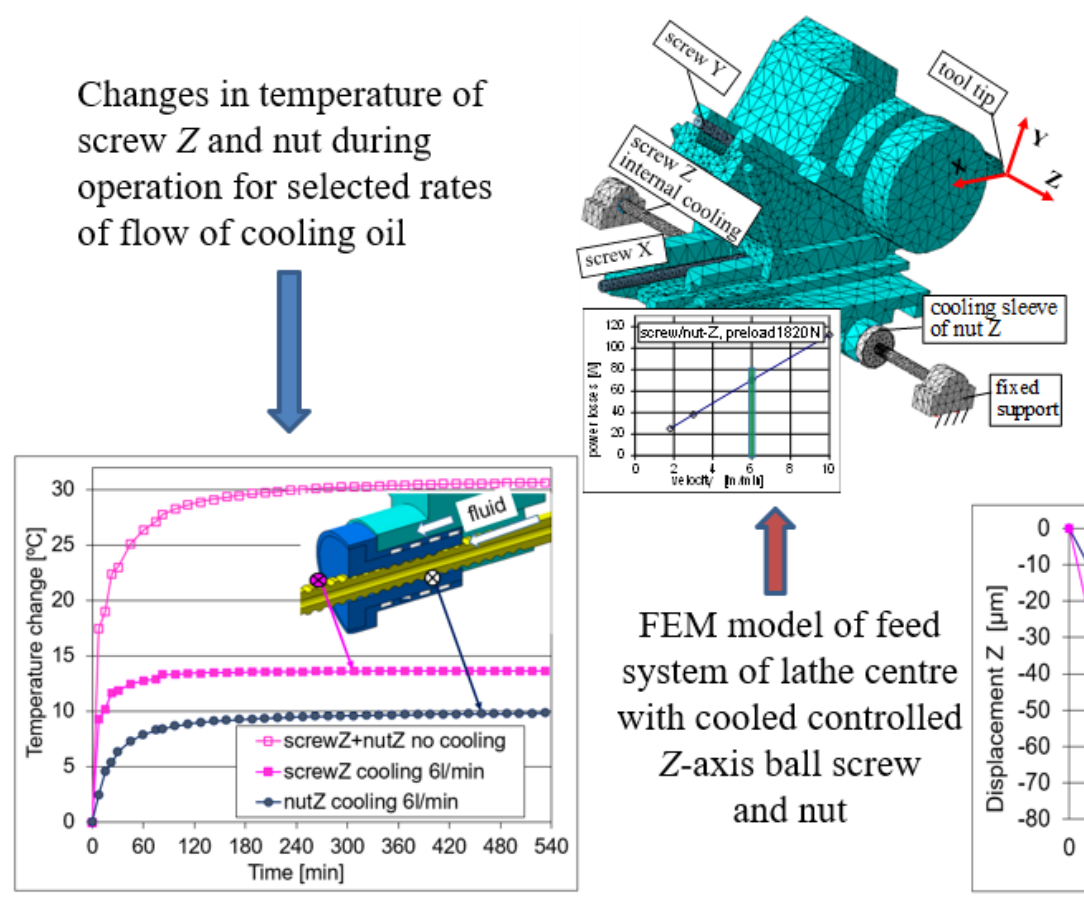

Thermal displacements $Z$ of tool tip during operation of feed axis $Z$ for selected rates of flow of cooling oil
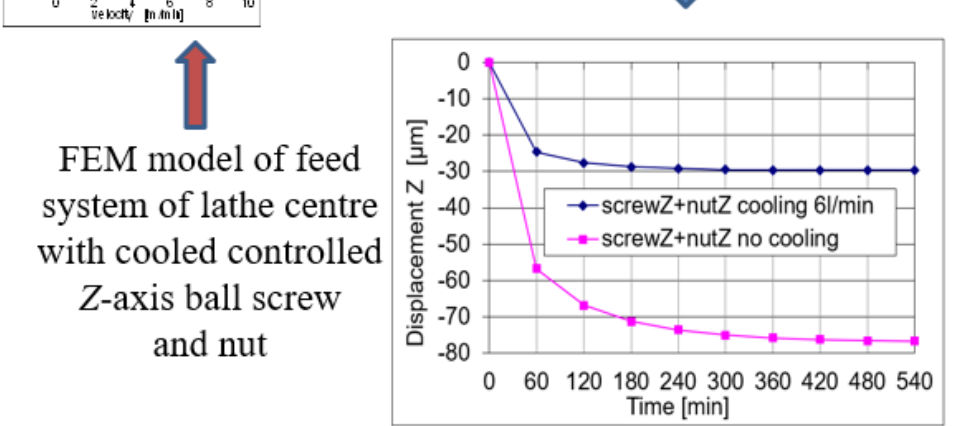

Fig. 24. Ball screw cooling effects

\section{CONCLUSIONS}

- The design of efficient forced cooling for the machine tool structure and the major heat sources requires a holistic modelling of the power losses as the basis for the design of cooling functions and heat exchangers and the specification of coolants, cooling parameters and control, monitoring and optimization procedures. 
- In order to ensure as high cooling efficiency as possible dedicated heat exchangers should be located as close as possible to the major heat sources.

- In order to maximally limit the machine tool's thermal errors through forced cooling the design of the latter should be based on advanced holistic thermal behaviour modelling, numerical simulations and optimization, mostly for the assurance of control axis precision.

- The efficiency of forced fluid cooling strongly depends on the complexity of heat sources, their location in the machine tool structure, heat accumulation and the thermal capacity of the deformed parts. In the case of complex machine tools, this efficiency, depending displacements, can reach:

- for total headstock cooling with spindle displacements $-71 \%$,

- for directly driven rotating table (controllable) axial displacements $-71 \%$,

- ball screw nut and shaft cooling $-62 \%$.

- Forced cooling is still important for increasing machine tool precision and should be developed towards intelligent cooling functions assuring maximum autonomy and limiting energy consumption.

- Further research on the optimal self-cooling of machine tool assemblies is needed and is worth supporting.

\section{ACKNOWLEDGMENTS}

The authors express their thanks to Doosan Infracore Co. for making it possible to test the model and for financially supporting this research.

\section{REFERENCES}

[1] JEDRZEJEWSKI J., POTRYKUS J., KWASNY W., 1972, Device for heat transfer from bearing nodes of machine tools, Patent No. 64570, (Polish).

[2] JEDRZEJEWSKI J., 1973, Zur Erwërmung von Drehmaschinen - Spindlkasten, Werkzeugmaschinen International, 4, 47-50.

[3] JEDRZEJEWSKI J., POTRYKUS J., 1968, Die Wärmeableitung an Werkzeugmaschinen Spindellagerungen, Maschinenbautechnik, 17/8, 423-426.

[4] JEDRZEJEWSKI J., KWASNY W., POTRYKUS J., 1989, Beurteilung der Berechnungsmethoden für die Bestimmung der Energieverluste im Wälzlagern, Schmierungstechnik, 20/8, 243-244.

[5] DE HAAS P., 1975, Möglichkeiten und Grenzen zur Kompensation thermischer Stoereinflussen bei Fertigungsystemen, ZwF, 70/7, 366-370.

[6] DE HAAS P., HEISEL U., 1978, Kompensation thermischer Deformationen an Werzeugmaschinen, ZwF, 73/11, 555-560.

[7] VYROUBAL J., 2010, Using the spindle cooling temperature as a tool for compensating the thermal deformation of machines, Acta Polytechnica, 50/1, 19-22.

[8] WINIARSKI Z., KOWAL Z., 2006, Investigation of the effects of heat generation in HSM electroheadstocks, Journal of Machine Engineering, 6/2), 107-115.

[9] WINIARSKI Z., KOWAL Z., BLAZEJEWSKI A., 2008, Decreasing of thermal errors in a lathe by forced cooling of ball screws and headstock, Journal of Machine Engineering, 8/4, 122-130.

[10] WINIARSKI Z., KOWAL Z., KWASNY W., HA J.-Y., 2010, Thermal model of the spindle drive structure, Journal of Machine Engineering, 10/4, 41-52.

[11] XIROUCHAKIS P., AVRAM O.I., ADHAM M., 2009, Machine tool cooling and lubrication in the use phase, Final Report, Swiss Federal Institute of Technology, Lausanne, 17 Jun., 1-24. 
[12] BRECHER C., BÄUMLER S., JASPER D., TRIEBS J., 2012, Energy efficient cooling systems for machine tools, 19th CIRP Int Conf on Life Cycle Engineering, Berkeley, 239-244.

[13] MIYAGUCHI K., ARAI S., 2013, State of the Art Ball Screw trends for Machine Tool Applications, Journal of SME-Japan, 13-18.

[14] XIA C., FU J., LAI J., YAO X., CHEN Z., 2015, Conjugate heat transfer in fractal tree-like channels network heat sink for high-speed motorized spindle cooling, Applied Thermal Engineering, 90, 1032-1042.

[15] UHLMANN E., PRASOL L., THOM S., SALEIN S., WIESE R., 2018, Development of dynamic model for simulation of a thermoelectric self-cooling system for linear direct drives in machine tools, Proceedings, CIRP Sponsored Conference on Thermal Issues in Machine Tools, Dresden, 75-91.

[16] UHLMANN E., SALEIN S., POLTE M., TRIEBEL F., 2020, Modelling of a thermoelectric self-cooling system based on thermal resistance networks for Linear direct drives in machine tools, Journal of Machine Engineering, 20/1, 43-57.

[17] HELLMICH A., GLANZEL J., PIERER A., 2018, Analysing and optimizing the fluidic tempering of machine tool frames, CIRP Sponsored Conference on Thermal Issues in Machine Tools, Dresden, 195-210.

[18] DENKENA B., BERGMAN B., KLEMME H., DOHLMANN D., 2018, Cooling potential of heat pipes and heat exchangers within a machine tool spindle, Proceedings, CIRP Sponsored Conference on Thermal Issues in Machine Tools, Dresden, 295-305.

[19] WEGENER K., MAYR J., MERKLEIN M., BERENS B-A., AOYAMA T., SULITKA M., FLEISCHER J., GROCHE P., KAFTANOGLU B., JOCHUM N., MOEHRING H-CH., 2017, Fluid elements in machine tools, CIRP Annals - Manufacturing Technology, 60, 611-634.

[20] JEDRZEJEWSKI J., WINIARSKI Z., HA J.Y., 2014, The modelling of liquid cooling for the efficient reduction of thermal errors in heavy duty machine tools, $11^{\text {th }}$ Int. Conf. on High Speed Machining, Sept. 11-12, Prague, Czech Rep., Techn. Univ. Prague Proc., 1-9.

[21] WINIARSKI Z., 2006, Thermal analyses in the design of the electrospindles of contemporary machine tools, Mechanik, 03, 230-234, (in Polish).

[22] KOWAL Z., WINIARSKI Z., 1990, Computer system for the analysis and optimization of the thermal displacements of machining centres, Przeglad Mechaniczny, 49/21-22, 42-46, (in Polish).

[23] JEDRZEJEWSKI J., KWASNY W., KOWAL Z., WINIARSKI Z., 2014, In-house system for holistic modelling of machine tool operating properties, The 2nd Int. Conf. on Systems and Informatics CSAI, 15-17 November, Shanghai, China; Ed. Yunfei Chen Danvers, MA: IEEE, 409-414.

[24] JEDRZEJEWSKI J., KOWAL Z., KWASNY W., WINIARSKI Z., 2019, Ball screw precise modelling with dynamics of loads and moving heat sources taken into account, Journal of Machine Engineering, 19/4, $27-41$. 